\title{
Reporte de un caso fatal de encefalitis autoinmunitaria asociada a teratoma ovárico
}

\section{Report of a fatal case of autoimmune encephalitis associated with an ovarian teratoma}

\section{Santiago Rueda-Espinel1', Julio Vargas-Anaya ${ }^{1}$ y Nathalia J. Gamarra-Ramírez²}

${ }^{1}$ Departamento de Ginecología y Obstetricia, Universidad Autónoma de Bucaramanga, Bucaramanga; ${ }^{2}$ Departamento de Cuidado Intensivo Clínico FOSCAL, Floridablanca. Santander, Colombia

\section{Resumen}

Introducción: El teratoma del ovario es el tumor de células germinales más frecuente. Entre sus complicaciones se describen algunos síndromes paraneoplásicos, como la encefalitis por anticuerpos contra el receptor $N$-metil-D-aspartato (NMDA). Caso clínico: Mujer de 22 años sin antecedentes de importancia que consulta por cuadro clínico de 4 días de evolución caracterizado por síntomas psiquiátricos y un episodio convulsivo. Se considera un cuadro de meningoencefalitis y se indica manejo antibiótico de amplio espectro y antiviral. Ante el deterioro se sospecha una encefalitis autoinmunitaria, se identifica un tumor anexial en los estudios imagenológicos compatible con teratoma y se confirma el diagnóstico con el hallazgo de anticuerpos NMDA en el líquido cefalorraquídeo. A pesar de su resección y manejo sistémico, fallece a los 5 meses. Discusión: La encefalitis autoinmunitaria asociada a un teratoma es inusual, pero es una complicación que debe sospecharse como diagnóstico de exclusión. La mayoría tienen un pronóstico favorable, aunque hasta una cuarta parte de los casos puede asociarse a daño irreversible en la corteza del hipocampo e incluso la muerte, principalmente cuando el diagnóstico y el tratamiento son tardíos. Conclusiones: Este caso es un reto clínico que representa un vacío en la evidencia actual, puesto que no existe un estándar de manejo de los teratomas. Se propone que, una vez diagnosticado un teratoma, se realice una cistectomía ovárica. Son necesarios más estudios para validar esta recomendación.

Palabras clave: Encefalitis antirreceptor N-metil-D-aspartato. Encefalitis. Trastornos psicóticos. Teratoma. Síndromes paraneoplásicos.

\section{Abstract}

Introduction: The ovarian teratoma is the most common cell germ tumor. Some paraneoplastic syndromes have been described, including the anti-N-methyl-D-aspartate (NMDA) receptor encephalitis as part of its complications. Case report: $A$ 22 years old female patient with no important medical history, consults due to an acute psychotic disorder and a convulsion. A meningoencephalitis was considered and broad-spectrum antibiotics and antivirals were started. Faced with deterioration, an autoimmune encephalitis is considered as well. Imaging studies revealed an ovarian teratoma and diagnosis was confirmed with antibodies against NMDA receptor in cerebrospinal fluid. Despite its resection and systemic management, the patient dies after 5 months. Discussion: The autoimmune encephalitis associated with an ovarian teratoma is rare, it's a complication that must be suspected as an exclusion diagnosis and most have a favorable prognosis, however up to a quarter of cases can be associated with irreversible damage to the hippocampal cortex and even death, mainly when late diagnosis and treatment are made. Conclusions: This case is a clinical challenge, no evidence is available since there is

Disponible en internet: $27-10-2021$

Fecha de recepción: 25-11-2020

Fecha de aceptación: 08-07-2021 DOI: 10.24875/RECHOG.M21000020
Rev Chil Obstet Ginecol. 2021;86(4):403-409

www. rechog.com

0048-766X / @ 2021 Sociedad Chilena de Obstetricia y Ginecología. Publicado por Permanyer. Éste es un artículo open access bajo la licencia CC BY-NC-ND (https://creativecommons.org/licenses/by-nc-nd/4.0/). 
Rev Chil Obstet Ginecol. 2021;86(4)

no standard for teratoma management. It is proposed that once a teratoma is diagnosed, an ovarian cystectomy is performed. Further studies are necessary to validate this recommendation.

Key words: Anti-N-methyl-D-aspartate receptor encephalitis. Encephalitis. Psychotic disorders. Teratoma. Paraneoplastic syndromes.

\section{Introducción}

Los tumores del ovario están compuestos por tres tipos principales de células: epiteliales, germinales y estromales ${ }^{1}$. El teratoma ovárico comprende el $95 \%$ de los tumores de células germinales ${ }^{2}$. Se caracteriza por presentar derivados de al menos dos capas germinales: ectodermo (piel, pelo, tejido neuronal, glándulas sebáceas), mesodermo (músculo, grasa) o endodermo (epitelio mucinoso o ciliado) ${ }^{3}$.

El teratoma maduro representa el $95 \%$ de los teratomas $^{4}$. Es un tumor benigno, también conocido como quiste dermoide compuesto por tejidos diferenciados ${ }^{2,5}$. Es la neoplasia ovárica más frecuente en las mujeres de 10 a 30 años $^{6}$, y es el tumor no epitelial benigno más frecuente. Suelen ser asintomáticos y en su gran mayoría se diagnostican ecográficamente de forma incidental ${ }^{2}$.

El teratoma inmaduro es conocido como teratoma maligno, teratoblastoma o teratoma embrionario². Representa el $1 \%$ de los tumores de células germinales ${ }^{4}$. Está compuesto por diferentes tejidos inmaduros. Según su grado de diferenciación, así será el riesgo de diseminación extraovárica y de recurrencia ${ }^{2}$. Otros tipos menos frecuentes son los teratomas de transformación maligna y el monodérmico altamente especializado?

Su manejo es quirúrgico y se indica cuando el tumor es sintomático, ante la sospecha de malignidad, si hay riesgo de torsión $(>6 \mathrm{~cm})$ o de infección, si hay hallazgos sugestivos de metástasis o cuando hay un crecimiento mayor de $1 \mathrm{~cm}$ durante un periodo de 6 meses de seguimiento ${ }^{8}$. La American Cancer Society recomienda la cistectomía ovárica en caso de lesiones no cancerosas y la salpingooforectomía unilateral con muestreo abdominopélvico en los casos en que se sospeche un tumor maligno ${ }^{9}$.

La complicación más frecuente es la torsión ovárica, la cual se describe en un $16 \%$ de los casos. Otras con menor frecuencia de presentación incluyen infección, compresión o rotura con peritonitis química secundaria, y pueden asociarse a síndromes paraneoplásicos, como anemia hemolítica autoinmunitaria y encefalitis por anticuerpos contra los receptores de N-metil-Daspartato (NMDA) ${ }^{1}$.

La encefalitis está caracterizada por una presentación clínica que incluye alteraciones neuropsiquiátricas, movimientos involuntarios complejos, convulsiones, hipertermia, fallo ventilatorio y alteraciones autonómicas, siendo la fluctuación del estado de consciencia y la complejidad de los movimientos involuntarios los elementos más constantes y llamativos ${ }^{10}$. Las crisis epilépticas, la discinesia orofacial y la protrusión de la lengua son características del síndrome ${ }^{3}$. Cerca de un $70 \%$ de los pacientes inician con una fase prodrómica que incluye cefalea, fiebre y síntomas del tracto respiratorio o digestivo. Antes de 2 semanas, el $77 \%$ presentan síntomas de la esfera mental, posteriormente se describen una etapa de no respuesta y otra de hipermotilidad, y por último una de recuperación ${ }^{11}$.

Se presenta el caso de una encefalitis autoinmunitaria con curso fatal que se habría originado por la producción de anticuerpos contra el receptor NMDA desde un teratoma ovárico.

\section{Caso clínico}

Mujer de 22 años sin antecedentes de importancia que consulta por un cuadro clínico de 4 días de evolución caracterizado por alteración del sueño, conducta desorganizada, episodios de heteroagresividad y un episodio convulsivo tónico sin relajación de esfínteres ni salivación. En la exploración física de ingreso se encuentra taquicárdica y febril, el resto de los signos vitales dentro de los límites normales, desorientada, somnolienta, con habla incoherente y alucinaciones visuales, auditivas y sensitivas.

Los laboratorios evidencian leucocitosis a expensas de neutrofilia, electrolitos, gases arteriales y pruebas de función renal y hepática en rangos de normalidad. La tomografía computarizada cerebral muestra edema difuso, sin otros hallazgos relevantes. Se realiza una punción lumbar con estudio del líquido cefalorraquídeo (LCR) que revela pleocitosis linfocitaria. Se considera meningoencefalitis viral o bacteriana, por lo que se inicia manejo antiviral y antibiótico de amplio espectro.

Durante su estancia, la paciente presenta deterioro del estado de consciencia asociado a picos febriles, crisis convulsivas recurrentes y falla ventilatoria, por lo que se realiza intubación orotraqueal para protección de la vía aérea y manejo del estatus epiléptico 


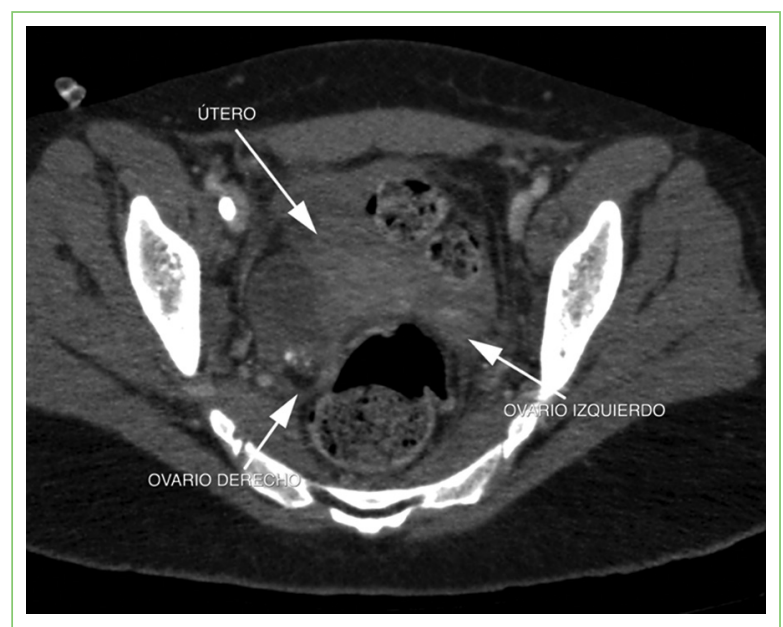

Figura 1. Tomografía computarizada abdominopélvica contrastada. La flecha blanca inferior derecha señala en el ovario derecho una lesión con densidades de grasa y calcificaciones. Las flechas blancas inferior izquierda y superior identifican, respectivamente, el ovario izquierdo y el útero normales.

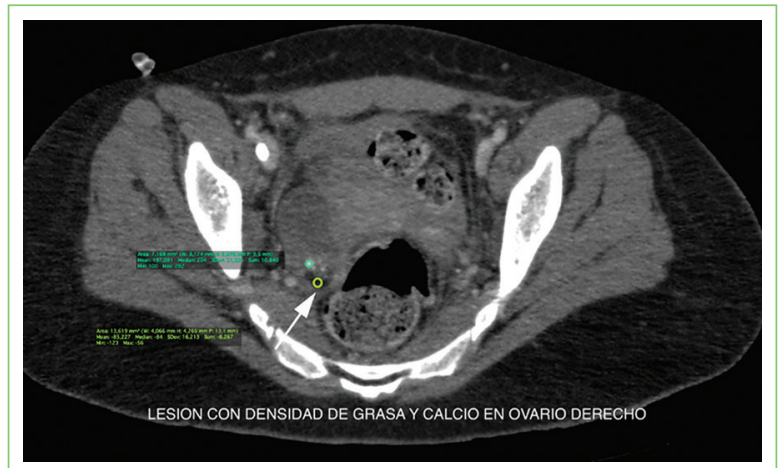

Figura 2. Tomografía computarizada abdominopélvica contrastada, en la cual se representan las densidades para tejido graso (-84 UH) y calcio (204 UH).

refractario. Se reciben estudios negativos para virus, bacterias y hongos en LCR y sangre.

Tres semanas posterior a su ingreso, ante la no mejoría, se decide realizar una tomografía corporal que identifica una imagen hipodensa dependiente del ovario derecho, de $4 \times 6 \mathrm{~cm}$, de aspecto quístico, tabicada, con presencia de una pequeña calcificación y otra área de densidad grasa, hallazgos que se confirman mediante ultrasonido transvaginal, sin evidencia de compromiso bilateral (Figs. 1 a 3). Se realiza resección por laparotomía. El reporte de patología informa teratoma maduro (Figs. 4 y 5) y se identifican anticuerpos

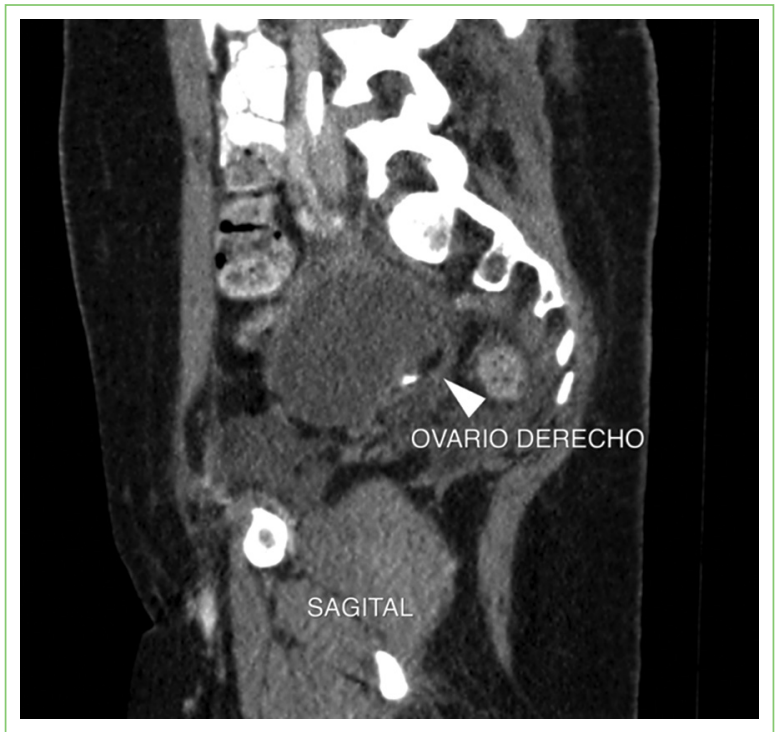

Figura 3. Tomografía computarizada abdominopélvica contrastada, corte sagital. La punta de flecha señala la lesión descrita en el ovario derecho con densidades de grasa y calcio.

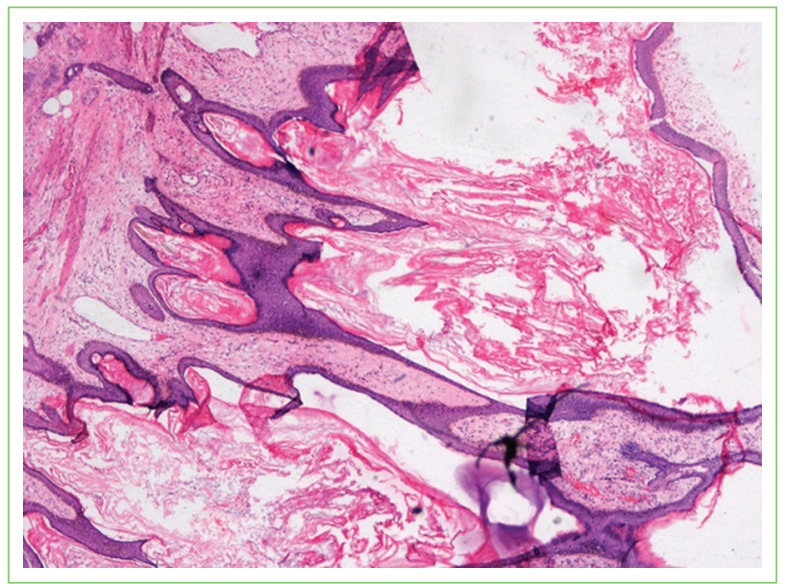

Figura 4. Lesión quística benigna rodeada por una cápsula de tejido fibroconectivo tapizada por epitelio escamoso estratificado queratinizante que recuerda la epidermis, con un espacio luminal ocupado por material eosinófilo compatible con queratina, secreción sebácea y detritus celulares. En el estroma colindante se observan estructuras anexiales.

positivos en LCR contra el receptor de NMDA, confirmando el diagnóstico.

Durante las siguientes semanas se realiza manejo con plasmaféresis (siete ciclos), inmunoglobulina, ciclofosfamida mensual por 5 meses, metilprednisolona y rituximab semanal por cuatro dosis, sin obtener mejoría 


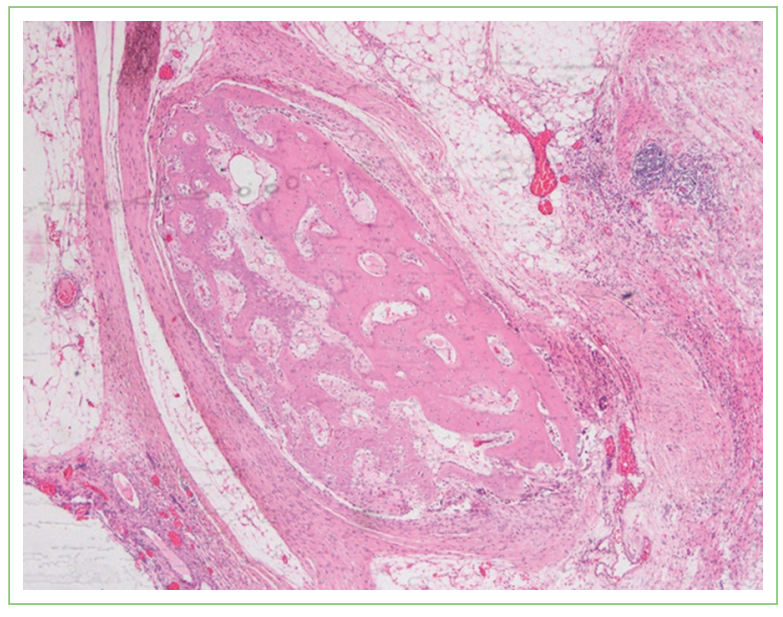

Figura 5. Trabéculas de hueso esponjoso maduro con osteocitos y tejido fibroconectivo sin elementos hematopoyéticos. Se reconoce también tejido adiposo maduro en la zona superior de la imagen.

clínica. La telemetría muestra ausencia de ritmos de alertamiento y la resonancia magnética cerebral reporta encefalitis hipocámpica bilateral autoinmunitaria. Posteriormente presenta una evolución tórpida dada por choque séptico de origen pulmonar, posible etiología nosocomial y bacteriemia por agente panresistente. Cinco meses después de su ingreso en la unidad de cuidados intensivos, presenta un paro cardiorrespiratorio y fallece.

\section{Discusión}

En la última década se han descrito aproximadamente 13 encefalitis de origen autoinmunitario, una de las cuales es la causada por anticuerpos contra los receptores $\mathrm{NMDA}^{12}$. El primer reporte de caso que hace alusión a esta afección data de 1997, en una mujer joven con un cuadro de encefalitis límbica y un teratoma ovárico asociado ${ }^{13}$. En 2007, Dalmau, et al. ${ }^{14}$ reportan una serie de 12 casos similares e identifican los autoantígenos diana de los anticuerpos (subunidades NR1 y NR2 de los receptores NMDA), denominando a la enfermedad encefalitis anti-NMDAR.

En 2020, Yaguchi, et al..$^{15}$, en un estudio realizado en una población de Japón, reportan una incidencia del $1.17 \%$ en las mujeres con un teratoma ovárico. El $60 \%$ presentan tumores subyacentes, de los cuales el $95 \%$ son teratomas ováricos (maduros e inmaduros) ${ }^{16}$. La relación hombre-mujer es de 9:91 y el 80\% se presenta en mujeres menores de 23 años.
Fisiopatológicamente se describe un ataque inmunitario contra el receptor NMDA, el cual está ubicado en la membrana celular y su función involucra la transmisión sináptica y la plasticidad neuronal ${ }^{17}$. Teniendo en cuenta que los teratomas tienen la potencialidad de estar compuestos por tejidos de los tres linajes celulares, se considera que la expresión de tejido nervioso desencadena la producción de anticuerpos antitumorales $^{18}$. Esto puede generar una interacción cruzada entre dichos anticuerpos y las subunidades NR1/2 del receptor en las neuronas del hipocampo, la corteza prefrontal, la amígdala y el hipotálamo ${ }^{11}$.

En 2019, dicha teoría fue demostrada in vitro por Dalmau, et al. ${ }^{19}$, quienes reportaron una intensa reacción antígeno-anticuerpo en la superficie celular de neuronas vivas de roedores ante la adición de LCR o suero de pacientes enfermos. El mismo año, Nolan, et al. ${ }^{20}$ describen que histopatológicamente se presenta una reacción compatible con un mecanismo autoinmunitario, caracterizada por agregados linfoides con centros germinales perineurogliales, ausencia casi total de neuronas maduras y presencia de astrocitos hipercelulares. Posteriormente, Chefdeville, et al..$^{21}$ encontraron una diferencia estadísticamente significativa $(p<0.001)$ en la presencia de tejido nervioso en los teratomas de pacientes enfermos ( $n=26 / 27)$, comparados con los controles $(n=16 / 40)$. Otro estudio ${ }^{22}$ lo ha identificado en el $100 \%$ de los enfermos $(n=3)$ y en ninguno de los controles $(n=19)$.

En 2020, Xu, et al. ${ }^{23}$ publicaron una cohorte china de 220 pacientes y reportaron que los síntomas más frecuentes fueron la psicosis $(82.7 \%)$ y las convulsiones $(80.9 \%)$, seguidas de fiebre $(57.3 \%)$, alteración del estado de consciencia (53.2\%), déficit de memoria $(48.2 \%)$, alteraciones del habla $(45.5 \%)$, movimientos desordenados (42.7\%), alteración del sueño (42.3\%) y cefalea (39\%), entre otros. La inestabilidad autonómica es más frecuente y grave en los adultos que en los niños ${ }^{11}$. Se reporta la necesidad de ingreso a la unidad de cuidados intensivos hasta en el $30 \%$ de los casos, y la necesidad de ventilación mecánica en el $20 \%{ }^{23}$.

En 2019, Al-Diwani, et al. ${ }^{24}$ publicaron una revisión sistemática que incluyó 464 pacientes y lograron agrupar las alteraciones neuropsiquiátricas en cinco categorías según la frecuencia de su presentación: alteración del comportamiento (68\%), psicosis (67\%), trastorno del ánimo (47\%), catatonía (30\%) y alteración de sueño (21\%). En el mismo año, Dai, et al..$^{25}$ identificaron una diferencia estadísticamente significativa en la presentación clínica de las pacientes con encefalitis anti-NMDAR asociada a teratoma y no asociada a 
Tabla 1. Banderas rojas para sospechar encefalitis por anticuerpos contra el receptor NMDA en un primer episodio psicótico

Banderas rojas
1. Psicosis o catatonia de inicio abrupto y evolución rápida y
grave en una persona previamente sana.
2. Alteraciones del habla.
3. Alteraciones en la función cognitiva, como atención o
memoria anterógrada.
4. Presencia de crisis epilépticas.
5. Presencia de movimientos anormales (discinesias orolinguales).
6. Alteraciones autonómicas graves.
7. Empeoramiento o complicaciones mayores con el uso de
antipsicóticos (síndrome neuroléptico maligno).
8. Presentaciones psiquiátricas atípicas que semejen delirio o
trastornos conversivos o disociativos.
Tomada y adaptada de Restrepo, et al. ${ }^{26}$.

teratoma, encontrando que en el primer grupo son más frecuentes la fiebre, la alteración del estado de consciencia, las arritmias, la hipoventilación central, los ingresos a la unidad de cuidados intensivos y la ventilación mecánica asistida.

Ante el descubrimiento de las encefalitis autoinmunitarias nace la necesidad de cambiar el abordaje diagnóstico de quienes se presentan a los servicios médicos con síntomas psiquiátricos. Por ello, la Asociación Colombiana de Psiquiatría publicó en 2019 las banderas rojas para sospechar encefalitis contra el receptor NMDA en un primer episodio psicótico ${ }^{26}$ (Tabla 1).

El diagnóstico se basa en la sospecha clínica y se confirma demostrando la presencia de anticuerpos contra el receptor NMDA en LCR o sangre, con una sensibilidad del $100 \%$ y el $85 \%$, respectivamente ${ }^{27}$. Las ayudas diagnósticas comprenden el examen citoquímico de LCR con pleocitosis a expensas de linfocitos (89-95\%), bandas oligoclonales $(60 \%)$ y proteinorraquia; electroencefalograma (EEG) con ondas deltas y theta, y en ocasiones convulsiones subclínicas; y resonancia magnética cerebral con hiperintensidad en T2 o en secuencia FLAIR en las áreas hipocampales, el cerebelo, la corteza, las regiones insulares, los ganglios basales y el tronco cerebral. La biopsia cerebral no ha demostrado ser útil. Una vez se sospecha el diagnóstico, hay que hacer una búsqueda activa de un tumor $^{18}$.

Los criterios diagnósticos propuestos en 2016 por Graus, et al. ${ }^{28}$ (Tabla 2) incluyen una serie de síntomas neuropsiquiátricos de los que se deben cumplir cuatro, sumados a una prueba de laboratorio alterada (citoquímico de LCR o EEG), y consideran que es un
Tabla 2. Criterios diagnósticos de Graus para encefalitis por anticuerpos contra el receptor NMDA

\begin{tabular}{|l|l|}
\hline $\begin{array}{l}\text { Probable } \\
\text { encefalitis } \\
\text { anti-NMDAR }\end{array}$ & $\begin{array}{l}\text { Todos deben estar presentes: } \\
\text { al menos cuatro de las siguientes categorías } \\
\text { mayores de síntomas: }\end{array}$ \\
$\begin{array}{l}\text { a. Comportamiento anormal (psiquiátrico) o } \\
\text { disfunción cognitiva } \\
\text { b. Alteración del habla } \\
\text { c. Convulsiones } \\
\text { d. Movimientos anormlaes, discinesias o } \\
\text { rigidez/posturas anormales } \\
\text { e. Disminución en el estado de consciencia } \\
\text { f. Disfunción autonómica o hipoventilación } \\
\text { central }\end{array}$ \\
\hline $\begin{array}{l}\text { 2. Al menos uno de los siguientes resultados } \\
\text { de laboratorio: }\end{array}$ \\
$\begin{array}{l}\text { a. Electroencefalograma anormal: actividad } \\
\text { desorganizada focal/lenta difusa, actividad } \\
\text { epiléptica o patrón delta-brush }\end{array}$ \\
\hline $\begin{array}{l}\text { b. Líquido cefalorraquídeo con pleocitosis o } \\
\text { bandas oligoclonales }\end{array}$ \\
\hline $\begin{array}{l}\text { 3. Exclusión de otras causas. } \\
\text { Confirmada } \\
\text { encefalitis } \\
\text { anti-NMDAR }\end{array}$ & $\begin{array}{l}\text { Anticuerpos IgG anti-Glun1 en presencia de } \\
\text { una o más de las categorías mayores de }\end{array}$ \\
\hline síntomas.
\end{tabular}

Tomada y adaptada de Graus, et al. ${ }^{28}$.

diagnóstico de exclusión una vez descartadas las causas infecciosas, inflamatorias, metabólicas y tóxicas (Tabla 3). Estos criterios fueron validados por Kaneko, et al. ${ }^{29}$ en 2018, identificando una sensibilidad del $87.2 \%$ y una especificidad del $96.7 \%$.

El tratamiento debe ser instaurado si se cumple la definición de caso probable, sin que sea necesario el resultado de los anticuerpos ${ }^{16}$. Se fundamenta en la extirpación del tumor, el uso de glucocorticoides (p. ej., prednisona), inmunoglobulinas y plasmaféresis ${ }^{30}$. Se describe que con esta primera línea de tratamiento presentan recuperación el $53 \%$ de las pacientes a las 4 semanas. En caso de no haber mejoría se procede a la segunda línea, conformada por rituximab o ciclofosfamida, o ambos, que logra la recuperación del 97\% a los 2 años ${ }^{18}$.

La mayoría tienen un pronóstico favorable, pero hasta una cuarta parte de los casos puede asociarse a daño irreversible en la corteza del hipocampo e incluso a la muerte, principalmente cuando el diagnóstico y el tratamiento son tardíos ${ }^{31}$. La atrofia cerebral difusa es reversible y no implica un pobre pronóstico, mientras que la atrofia cerebelosa es irreversible y se asocia con malos desenlaces ${ }^{32}$. Se describen tasas de mortalidad del $4-7 \%$ y tasas de recurrencia de hasta el $12-24 \%{ }^{33}$. En los casos que presentan mejoría se recomienda un seguimiento cada 6 meses por 4 años, ya 
Rev Chil Obstet Ginecol. 2021;86(4)

Tabla 3. Diagnóstico diferencial para síntomas agudos sugestivos de encefalopatía

1. Infecciosas: virus herpes simple, micoplasma, enterovirus, virus herpes 6, virus de Epstein-Barr, influenza.

2. Autoinmunitarias/inflamatorias: ADEM, anti-NMDAR, anti-LGI1, anti-AMPA, anti-CASPR2 y otras posinfecciosas 0 parainfecciosas, lupus eritematoso sistémico, vasculitis.

3. Tóxicas: ketamina, fenciclidina, MDMA, catinona, cannabinoides, hongos, síndrome serotoninérgico.

4. Efectos adversos de drogas antipsicóticas: síndrome neuroléptico maligno, discinesia tardía, reacción distónica aguda.

5. Trastornos psiquiátricos primarios: psicosis, trastorno depresivo mayor con episodio psicótico, síndrome de Kleine-Levin.

6. Condiciones epileptogénicas: estatus epiléptico no convulsivo, síndrome de epilepsia relacionado con infección febril (FIRES).

7. Migraña confusional aguda.

8. Trastorno de movimiento posinfección.

9. Problema psicógeno.

Tomada y adaptada de Abe, et al..$^{37}$.

que la aparición del tumor puede ser posterior al inicio de la encefalitis ${ }^{34}$.

En cuanto a la prevención de su aparición, Mangler, et al. ${ }^{35}$ plantearon (de ser posible) detectar el riesgo de desarrollar encefalitis al realizar la búsqueda de anticuerpos séricos en las pacientes asintomáticas con un teratoma ovárico; sin embargo, en una cohorte con 15 meses de seguimiento encontraron ausencia de seroprevalencia de anticuerpos en todas las pacientes $(n=80)$. Otra opción es la resección temprana de un teratoma ovárico, puesto que se han descrito casos incluso con tumores tan pequeños como de $8 \mathrm{~mm}^{12}$; no obstante, también se han descrito casos de aparición posterior a su extirpación en pacientes asintomáticas al momento de la cirugía ${ }^{36}$.

\section{Conclusiones}

La encefalitis autoinmunitaria asociada a un teratoma ovárico es infrecuente, pero hasta una cuarta parte de los casos tiene el potencial de generar secuelas neurológicas e incluso la muerte. Se desconoce la forma de prevenirla o anticiparla, lo cual destaca la importancia de definir su resección en una paciente asintomática. No existe un estándar de manejo quirúrgico. Actualmente se indica en los casos sintomáticos, ante la presencia de signos sugestivos de malignidad y cuando hay riesgo de torsión, siendo este último mayor en los tumores con diámetros de $6 \mathrm{~cm}$ o más.

El tamaño del tumor no representa una mayor 0 menor asociación con la presentación de encefalitis. En la literatura se han descrito casos con diámetros menores de $1 \mathrm{~cm}$, contrario a su relación directamente proporcional con la destrucción del tejido ovárico normal. Esto permite concluir que el tamaño no debe ser el parámetro que determine la resección en las pacientes asintomáticas. Por lo anterior, y con el objetivo de brindar un manejo oportuno, se propone que una vez diagnosticado un teratoma se realice una cistectomía ovárica. Son necesarios más estudios para determinar la validez de esta recomendación.

\section{Financiamiento}

Los autores declaran que no hay fuentes de financiamiento.

\section{Conflicto de intereses}

Los autores declaran que no hay conflictos de intereses.

\section{Responsabilidades éticas}

Protección de personas y animales. Los autores declaran que para esta investigación no se han realizado experimentos en seres humanos ni en animales.

Confidencialidad de los datos. Los autores declaran que han seguido los protocolos de su centro de trabajo sobre la publicación de datos de pacientes.

Derecho a la privacidad y consentimiento informado. Los autores han obtenido el consentimiento informado de los pacientes y/o sujetos referidos en el artículo.

\section{Bibliografía}

1. Penick ER, Hamilton CA, Maxwell GL, Marcus CS. Tumores de células germinales y el estroma, y otros tumores ováricos. En: Oncología ginecológica clínica. 9.르 ed. Madrid: Elsevier España; 2018. p. 290-313.

2. Coto Chaves $C$, Jiménez Víquez M, Naranjo Alfaro $S$. Teratoma: masa anexial en mujeres jóvenes. Rev Med Sinerg. 2019;4:31-9.

3. Jiménez-Ruiz A, Cárdenas-Sáenz O, Ruiz-Sandoval J. Encefalitis autoinmunitaria secundaria a teratoma ovárico: un nuevo síndrome neuropsiquiátrico. Reporte de caso. Ginecol Obstet Mex. 2017;85:472-9.

4. Gershenson D. Ovarian germ cell tumors: pathology, clinical manifestations and diagnosis. UpToDate; 2019. Disponible en: https://www.uptodate.com/contents/ovarian-germ-cell-tumors-pathology-clinical-manifesations-and- diagnosis

5. Pons LM, García O, Salmon A, Macías MM, Guerrero CM. Tumores de ovario: patogenia, cuadro clínico, diagnóstico ecográfico e histopatológico. Medisan. 2012;16:920-31. 
6. Hoffman M, Hochberg L. Differential diagnosis of the adnexal mass. UpToDate; 2019. Disponible en: https://www.uptodate.com/contents/differential-diagnosis-of-the-adnexal-mass

7. Dan V, Zacharias R, Martins V, Genaro A. Teratoma ovariano imaturo gigante com teratoma maduro bilateral: relato do caso. Med (Ribeirao Preto). 2016;49:483-9.

8. Muto M. Management of an adnexal mass. UpToDate; 2019. Disponible en: https://www.uptodate.com/contents/management-of-an- adnexal-mass

9. Equipo de redactores y editores médicos de la Sociedad Americana Contra El Cáncer. Cáncer de ovario, ¿Qué es el cáncer de ovario? Am Cancer Soc. 2016;16(1-73):73.

10. Reyes-Botero G. Encefalitis paraneoplásica por anticuerpos contra el receptor de NMDA. Remisión completa después de la resección de un teratoma ovárico. Rev Neurol. 2011;52:536-40.

11. Liang Z, Yang S, Sun X, Li B, Li W, Liu Z, et al. Teratoma-associated anti-NMDAR encephalitis: two cases report and literature review. Medicine (Baltimore). 2017;96:e9177.

12. Lwanga A, Kamson DO, Wilkins TE, Sharma V, Schulte JJ, Miller J, et al. Occult teratoma in a case of $\mathrm{N}$-methyl-D-aspartate receptor encephalitis. Neuroradiol J. 2018;31:415-9.

13. Greiner H, Leach J, Lee K, Krueger D. Anti-NMDA receptor encephalitis presenting with imaging findings and clinical features mimicking Rasmussen syndrome. Seizure. 2011;20:266-70.

14. Dalmau J, Tuzun E, Wu H, Masjuan J, Rossi J, Voloschin A, et al. Paraneoplastic Anti-N-methyl-D-aspartate receptor encephalitis associated with ovarian teratoma. Ann Neurol. 2007;61:25-36.

15. Yaguchi H, Tsuji T, Yabe I, Hirayama E, Nomura T, Ohashi I, et al. Incidence of anti-NMDAR encephalitis in patients undergoing resection of ovarian teratoma in a single institution. J Neurol Sci. 2020;409:116608.

16. Reyna-Villasmil E, Mayner-Tresol G, Herrera-Moya P. Anti-N-methyl-D-aspartate-receptor encephalitis due to ovarian teratoma. Med Clin (Barcelona). 2017;149:560-1.

17. González-Valcárcel J, Rosenfeld M, Dalmau J. Diagnóstico diferencial en la encefalitis por anticuerpos contra el receptor NMDA. Neurologia. 2010;25:409-13.

18. Suarez DV, Rojas JP, Castillo GE, Díaz E, Montero FJ. Encefalitis por Anticuerpos contra el Receptor N-metil D-aspartato (NMDAR) en Pediatría. Reporte de caso y revisión de la literatura. Acta Neurol Colomb. 2014;30:193-9.

19. Dalmau J, Armangué T, Planagumà J, Radosevic M, Mannara F, Leypoldt F, et al. An update on anti-NMDA receptor encephalitis for neurologists and psychiatrists: mechanisms and models. Lancet Neurol. 2019;18:1045-57.

20. Nolan A, Buza N, Margeta M, Rabban JT. Ovarian teratomas in women with anti-N-methyl-D-aspartate receptor encephalitis topography and composition of immune cell and neuroglial populations is compatible with an autoimmune mechanism of disease. Am J Surg Pathol. 2019;43:949-64.

21. Chefdeville A, Treilleux I, Mayeur ME, Couillault C, Picard G, Bost C et al. Immunopathological characterization of ovarian teratomas associated with anti-N-methyl-D-aspartate receptor encephalitis. Acta Neuropathol Commun. 2019;7:38.
22. Tabata E, Masuda M, Eriguchi M, Yokoyama M, Takahashi Y, Tanaka K, et al. Immunopathological significance of ovarian teratoma in patients with anti-N-methyl-D-aspartate receptor encephalitis. Eur Neurol. 2014;71:42-8

23. Xu X, Lu Q, Huang Y, Fan S, Zhou L, Yuan J, et al. Anti-NMDAR encephalitis: a single-center, longitudinal study in China. Neurol Neuroimmunol Neuroinflamm. 2019;7:e633.

24. Al-Diwani A, Handel A, Townsend L, Pollak T, Leite MI, Harrison PJ, et al. The psychopathology of NMDAR-antibody encephalitis in adults: a systematic review and phenotypic analysis of individual patient data. Lancet Psychiatry. 2019;6:235-46.

25. Dai Y, Zhang J, Ren H, Zhou X, Chen J, Cui L, et al. Surgical outcomes in patients with anti-N-methyl-D-aspartate receptor encephalitis with ovarian teratoma. Am J Obstet Gynecol. 2019;221:485.e1-10.

26. Restrepo Martínez M, Paola Bautista G, Espínola-Nadurille M, Bayliss L. Banderas rojas para sospechar encefalitis anti-NMDAr en un primer episodio psicótico: reporte de dos casos. Rev Colomb Psiquiatr. 2019:48:127-30.

27. Höftberger R, Van Sonderen A, Leypoldt F, Houghton D, Geschwind M, Gelfand J, et al. Encephalitis and AMPA receptor antibodies. Novel findings in a case series of 22 patients. Neurology. 2015;84:2403-12.

28. Graus F, Titulaer MJ, Balu R, Benseler S, Bien CG, Cellucci T, et al. A clinical approach to diagnosis of autoimmune encephalitis. Lancet Neurol. 2016;15:391-404.

29. Kaneko A, Kaneko J, Tominaga N, Kanazawa N, Hattori K, Ugawa Y, et al. Pitfalls in clinical diagnosis of anti-NMDA receptor encephalitis. J Neurol. 2018;265:586-96.

30. Bai $Y$, Guan $Q$, Jiang J, Zhang Z. Treatment principles of ovarian teratoma with anti-N-methyl-d-aspartate receptor encephalitis. Arch Gynecol Obstet. 2016;294:623-9.

31. Bhat $P$, Ahmed A, Jolepalem $P$, Sittambalam C. A case report: anti-NMDA receptor encephalitis. J Community Hosp Intern Med Perspect. 2018;8:158-60.

32. lizuka T, Kaneko J, Tominaga N, Someko H, Nakamura M, Ishima D, et al. Association of progressive cerebellar atrophy with long-term outcome in patients with Anti-N-methyl-D-aspartate receptor encephalitis. JAMA Neurol. 2016;73:706-13.

33. Barry H, Byrne S, Barrett E. Anti-N-methyl-D-aspartate receptor encephalitis: review of clinical presentation, diagnosis and treatment. $\mathrm{Br} \mathrm{J}$ Psych Bull. 2015;39:19-23.

34. Omata T, Kodama K, Watanabe Y, lida Y, Furusawa Y, Takashima A, et al. Ovarian teratoma development after anti-NMDA receptor encephalitis treatment. Brain Dev. 2017;39:448-51.

35. Mangler M, Trebesch De Perez I, Teegen B, Stöcker W, Prüss H, Meisel A, et al. Seroprevalence of anti-N-methyl-D-aspartate receptor antibodies in women with ovarian teratoma. J Neurol. 2013:260:2831-5.

36. Jandu AS, Odor PM, Vidgeon SD. Status epilepticus and anti-NMDA receptor encephalitis after resection of an ovarian teratoma. J Intensive Care Soc. 2016;17:346-52.

37. Abe KK, Koli RL, Yamamoto LG. Emergency department presentations of anti-N-methyl-D-aspartate receptor encephalitis. Pediatr Emerg Care. 2016;32:107-12 